\title{
A NEW TYPE OF OXYGEN CHAMBER
}

\author{
BY ALVAN L. BARACH
}

(From the Department of Medicine, College of Physicians and Surgeons, Columbia University, and the Presbyterian Hospital)

(Received for publication April 26, 1926)

During the last decade the therapeutic use of oxygen has received considerable attention. The physiologic basis for its use has been reviewed by Means (1) and by Lundsgaard (2). In a recent communication (3) we have discussed the efficacy of various types of portable apparatus and the clinical results obtained from adequate oxygen therapy. We wish now to report a new type of oxygen chamber in which the ventilation is secured by a thermal circulation of the air.

An oxygen chamber may be defined as a room which is leak-tight in order to provide an atmosphere rich in oxygen and which is artificially ventilated in order to maintain a comfortable environment. The oxygen content of the room is raised until the concentration of oxygen is between 40 and 60 per cent, which is considered the therapeutic range. It is ventilated in order to remove excess carbon dioxide, moisture and heat. Provision is made to keep the $\mathrm{CO}_{2}$ concentration below 1.0 per cent, maintain a temperature between $58^{\circ}$. and $68^{\circ} \mathrm{F}$., and secure a relative humidity between 50 and 70 per cent.

These conditions have been met previously by the construction of a room within a room. The inside room, or oxygen chamber, is ventilated by means of motors, one to four in number, which operate a corresponding number of air pumps or fans. In addition, a refrigerating plant or frigid air system is present for removal of heat and moisture. All the machinery is kept outside the chamber, at times in a separate room. The air is pumped out of the chamber, passed through soda-lime and over coils of ammonia or brine, and then returned to it (4).

The chamber which we are reporting differs from the above in that there are no pumps, fans, motors, artificial refrigerating plant, or any electrical appliance. In addition, the chamber is transportable. It is 
constructed of aluminum and glass panels, which are joined together with the intervention of rubber gaskets and bolted in place. The inside of the chamber is lined in certain places by aluminum pipe which contains circulating cold water from the ordinary cold water faucet. The water enters the pipe at one side of the chamber and leaves at the other. The exit water returns to the drain. A large soda-lime container is placed under the bed. No other apparatus is used.

The air in contact with the cold aluminum pipes is chilled, the moisture is condensed on the surface of the pipes, and the cool dry air passes to the floor of the chamber where the carbon dioxide is removed by contact with the soda-lime. The air is warmed by the heat of the patient's body and passes to the roof with additional moisture and carbon dioxide. It is then chilled again and the process is repeated. By the use of these convection currents there is obtained an adequate removal of carbon dioxide, moisture and heat.

\section{CONSTRUCTION OF THE CHAMBER}

The dimensions of the chamber are 10 feet long, 7 feet high and $5 \frac{1}{2}$ feet wide. The two side walls are composed of panels 7 feet high and $2 \frac{1}{2}$ feet in width. The head end contains two panels 7 feet high and $2 \frac{3}{4}$ feet wide. The foot end is made in a solid piece to enclose a door $6 \frac{1}{2}$ feet high and 44 inches in width. The floor and roof of the chamber are composed of panels $5 \frac{1}{2}$ feet long and $2 \frac{1}{2}$ feet wide. In one of the side panels nearest the foot end a smaller door has been constructed $6 \frac{1}{2}$ feet high and 2 feet wide. The remaining side panels havea window in the upper half, 3 feet high and 2 feet wide. The glass is of the triplex variety, i.e., two thicknesses of glass with celluloid between, which is exceedingly strong and does not splinter.

The aluminum panels have to be made with especial care to obtain strength, lightness, durability and a leak-tight juncture. An aluminum sheet of the dimensions of the panel desired is welded on all four sides to an aluminum angle. The sheet is 0.030 of an inch in thickness, whereas the angle is 0.25 of an inch in thickness. The welding of materials of such difference in thickness is very difficult and requires a highly trained aluminum welder. The angle is 1 inch by 1 inch. Each aluminum sheet is thus set in a frame which consists of the aluminum angle. The side of the angle which projects outward is then 
lined with a rubber gasket and the adjoining panels bolted together. This method of construction applies through the chamber with the exception of the floor and doors which are reenforced by strip aluminum rods.

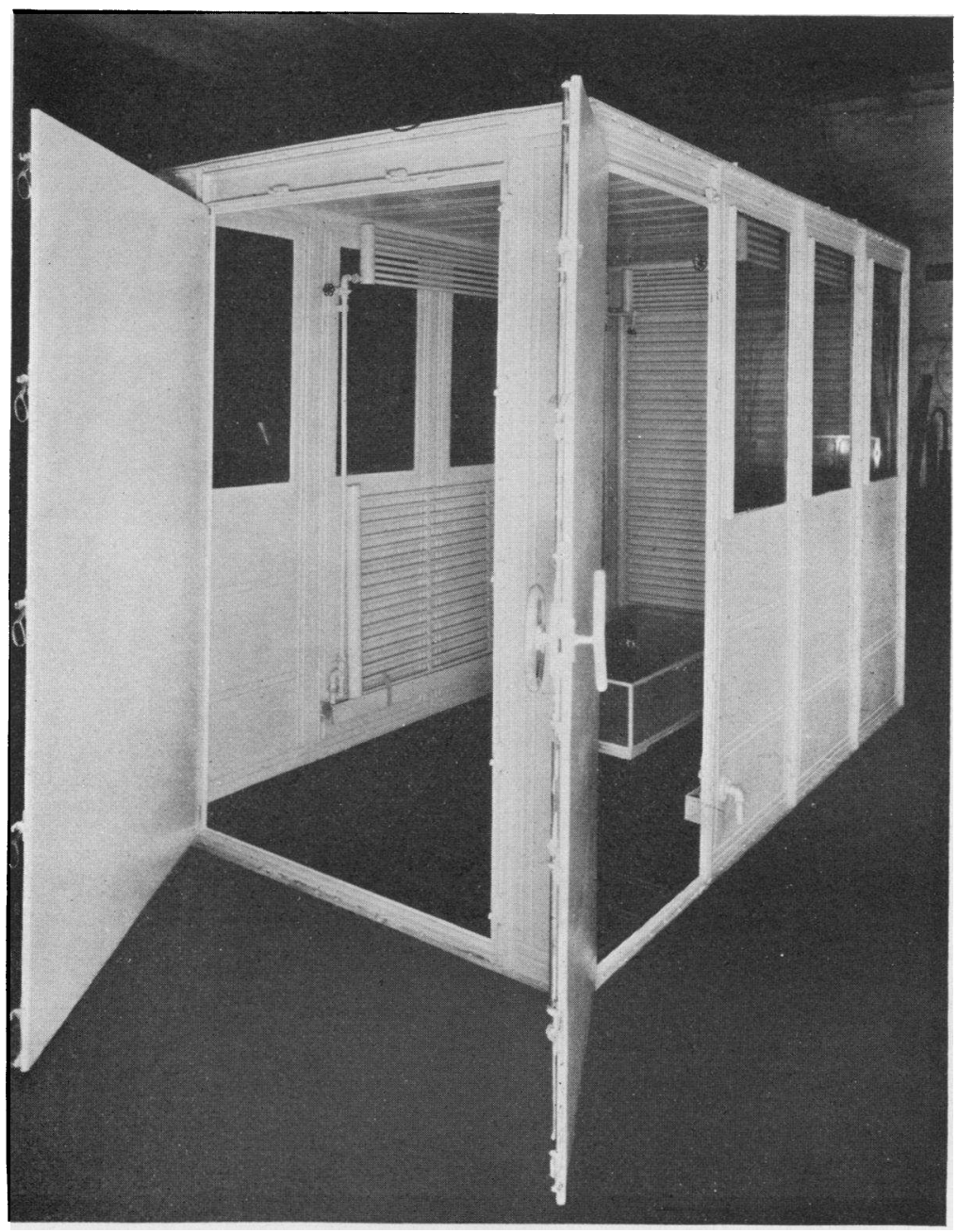

Fig. 1. Oxygen Chamiber, Showing Two Doors, Coils and Soda-Lime Box

The inside of the chamber contains several banks of coils, the disposition of which is seen in figures 1 and 2. The head end contains 
a solid bank of pipe from the roof to 8 inches from the bottom and extending in width to within 6 inches from each wall. At the sides

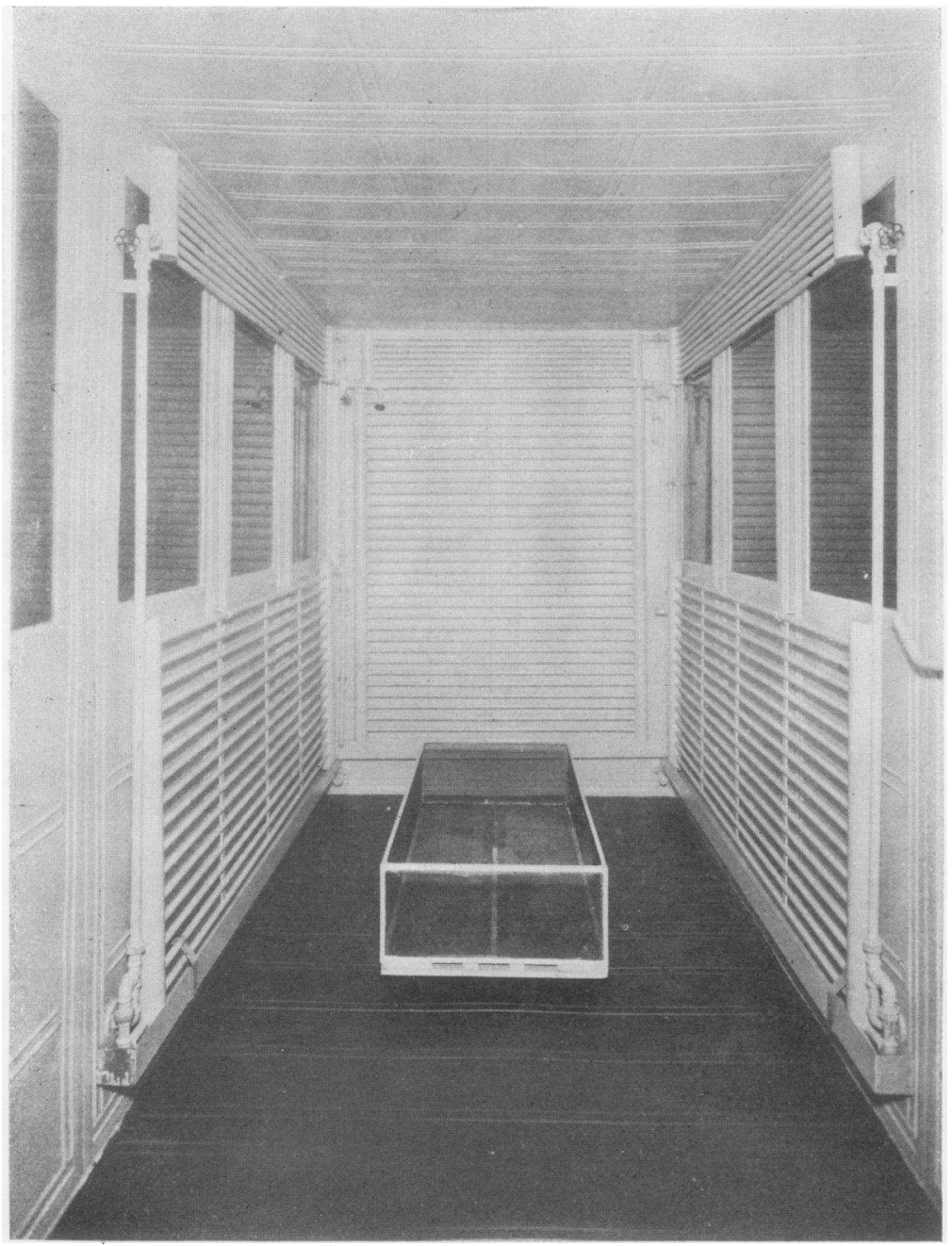

Fig. 2. Interior of Oxygen Chamber

Pipes line three walls. Soda-lime box is placed under the bed

there are two banks of coils, one at the top, $1 \frac{1}{2}$ feet in height and 7 feet in length, and one at the bottom, 3 feet in height and 7 feet in length. The foot end of the chamber and both sides for a distance of 3 feet 
adjacent to the foot end are free from any coils. The pipe is $\frac{1}{2}$ inch in outside diameter. Each bank of coils is equipped with a valve so that they may be used all together or one at a time as is desired. At the bottom of the coils is an aluminum trough which conveys the condensed water to the outside by means of a pipe water-sealed.

The soda-lime box is 4 feet long, 2 feet wide and 1 foot high and is made of copper screening, supported by aluminum rods 1 inch in width. Two trays of the same material are suspended in the box to increase the area of soda-lime exposed. The box is placed at the head end of the chamber underneath the bed.

Four $\frac{1}{4}$-inch holes are placed at the head end of the chamber for withdrawal of air for testing of oxygen and carbon dioxide. The simplified oxygen analyzer described by Binger (4) is used and an early Henderson modification of Haldane's $\mathrm{CO}_{2}$ analyzer. For routine use Marriott and Howland's phenolsulphonephthalein test is employed for determining $\mathrm{CO}_{2}$ concentration. Two $\frac{3}{8}$-inch holes are placed in the head end for admission of oxygen.

\section{THE OPERATION OF THE CHAMBER}

The assemblage of the chamber is accomplished simply by bolting the panels in place in their respective positions. When a patient is put in the chamber the large door is used, and either the patient is transferred on a stretcher to a bed in the chamber or the bed containing the patient is rolled in. A can of soda-lime is emptied in the box, 50 pounds being distributed in three layers. This is sufficient to last approximately one week. If it is planned to keep the patient in the chamber two weeks two cans may be emptied in the soda-lime box. The valve regulating the inlet of cold water is turned on full, and may later be regulated to a slower flow if the room temperature falls below $58^{\circ} \mathrm{F}$. The oxygen is first admitted at the rate of 30 liters per minute until the concentration reaches the desired level, and then adjusted to between 6 and 10 liters per minute depending on the amount required.

The small door at the side is used for entrance of doctor and nurse. A curtain of rubberized silk is suspended inside this door to prevent loss of oxygen when entering or leaving the chamber. When leaving the chamber it is advisable to get between the curtain and the door 
before opening the door, allowing the curtain to block the free diffusion of air and oxygen when the door is opened.

The inflow of oxygen is regulated by a specially calibrated reducing valve which is connected by a manifold to five high pressure oxygen tanks. Each tank contains 6000 liters. The valve is calibrated in liters per minute. The amount of oxygen needed for a given length of time can be calculated and the oxygen tanks renewed accordingly.

\section{VEN'TILATION DATA OF THE CHAMBER}

Good ventilation depends upon the maintainance of an atmosphere of such temperature, humidity and state of motion as will cool the human body without chilling it. The standard in use under ordinary circumstances includes a temperature of from $65^{\circ}$ to $70^{\circ} \mathrm{F}$., a humidity between 50 and 70 per cent, and an absence of drafts of cold air. The oxygen and carbon dioxide concentrations are no longer considered criteria of the hygienic purity of the air as these factors do not play a rôle until long after the atmosphere has become oppressive from other causes, such as heat, moisture and odor.

Human comfort is dependent upon the rate of heat production within the body and the cooling power of the air. There is a constant loss of heat from the surface of the body by radiation, convection and evaporation. Lowering the temperature of the air increases the cooling power by accelerating radiation and convection, whereas lowering the humidity increases the cooling power by accelerating evaporation. The health, comfort, and physiological efficiency of men exposed to atmospheres of varying temperature and humidity have been investigated by the U. S. Bureau of Mines in coöperation with the American Society of Heating and Ventilating Engineers (5). They have found that certain combinations of temperatures and humidites will produce the same total body heat loss, by radiation, convection and evaporation, and therefore the same feeling of comfort and discomfort. Lines passing through such air conditions, plotted in the form of a psychrometric chart, they have designated equal comfort or effective temperature lines (6). Thus, a temperature of $65^{\circ} \mathrm{F}$. with a relative humidity of 100 per cent is equally as comfortable as a temperature of $70^{\circ} \mathrm{F}$. with 50 per cent relative humidity or a temperature of $78^{\circ} \mathrm{F}$. with 0 
relative humidity. This particular line they have designated the comfort line for still air conditions.

Effective temperature appears to be a very valuable term for defining conditions of the atmosphere inasmuch as it represents the cooling power of the air and is capable of exact definition. For patients with fever we believe the effective temperature should be lower. (See table 1 for ventilation data.) The temperature of the chamber is kept at $60^{\circ} \mathrm{F}$. with a relative humidity of 60 per cent, which corresponds on the effective temperature line to a temperature of $57^{\circ} \mathrm{F}$. with 100 per cent humidity or a temperature of $66^{\circ} \mathrm{F}$. with zero humidity. By regulating the flow of cold water and the number of banks of coils employed both the temperature and humidity may be lowered or increased.

Leonard Hill (7) has made an exhaustive study of the science of ventilation through the development of a new instrument, the katathermometer. The cooling-power of the air and the velocity of air movement may be determined by its use. As these factors are of profound importance in estimating good ventilatory conditions the kata-thermometer was used to determine the effectiveness of the chamber in these respects.

The kata-thermometer is a specially constructed alcohol thermometer with a cylindrical bulb $1.8 \mathrm{~cm}$. in diameter and $2.2 \mathrm{~cm}$. in length. The stem, $20 \mathrm{~cm}$. in length, is graduated in tenths of a degree Fahrenheit from 100 to 95 . The procedure followed in taking a reading is to heat the kata in water until the alcohol rises to the top. The bulb is then dried and the instrument set up firmly in a suitable position. The time is taken for the fluid to fall from 100 to 95 , measured by a stop-watch. This time is a function of the heat loss from the surface of the kata by radiation and convection. To take the wet readings a muslin finger-stall is put on the bulb, and the same procedure followed. The wet kata gives the heat loss from radiation, convection and evaporation. As the total heat lost from the surface of the kata in cooling from 100 to 95 is always the same, the rate of heat loss depends entirely upon the surrounding atmospheric conditions, namely, temperature, humidity, and air movement.

The total heat loss in cooling from 100 to 95, determined experimentally in millecalories, divided by the surface area of the kata gives 
the heat loss in millecalories per square centimeter. This figure is known as the "kata factor," and constitutes the converting constant of the reading of any kata-thermometer in millecalories per square centimeter.

Thus, if $F$ equal the total heat loss per square centimeter and $T$ equal the number of seconds taken by the kata to cool from $100^{\circ}$ to $95^{\circ} \mathrm{F}$. in an atmosphere with a temperature $t$, the heat loss can be expressed according to the law of cooling of hot bodies by the formula

$$
\begin{aligned}
& F=K(\phi-t) T \text { or in an individual instance, } \phi \text { being } 36.5, \\
& F=0.27(36.5-17.8) 105.9=535, \text { or the kata factor }
\end{aligned}
$$

The rate of cooling per square centimeter per second is then given by

$$
H=\frac{F}{T} \text { or } K(\phi-t), \text { in millicalories. }
$$

To calculate the wind velocity from the dry kata reading the following formula is used.

$$
\frac{H}{(\phi-t)}=0.27+0.49 \sqrt{ } \bar{V}
$$

$V$ can be determined in meters per second or feet per minute. The above explanation indicates the method used and will suffice for the purposes of this paper. A more detailed study may be found in Hill's book or in a recent paper by McConnell and Yaglaglou (8).

Air movements have been explored by means of mechanical vane anemometers and by the inclination from the vertical of paper flags or silk threads, or by the drift of small balloons. As Hill says, none of these methods appreciates as the kata does every eddy, no matter how small and brief, which go to make up the sum total of the movements which affect the skin. "Thus fallacious results may be obtained on comparing the air movement in a room ventilated by the plenum system, which is more unidirectional in character and affects flags, and the movement in a room with open windows in which there are eddies, which neutralize any steady inclination of flags. The kata, then, seems to be a suitable instrument for measuring the physiological efficiency of air movement in rooms." He believes that a dry kata heat loss of 6 millecalories per square centimeter per second constitutes 
a good standard of comfort for office and residential buildings. This would ordinarily require an open window or some system of artificial ventilation.

The efficiency of the chamber was determined from this point of view and the data tabulated in table 1 . It is seen that the cooling power varied between 5.8 and 7.3 millecalories per square centimeter per second, with an average approximately of 6.5 . The cooling power is about 1 millecalorie higher at the floor than at the roof. This is explained by the temperature being 7 degrees lower at the floor than at the roof. The relative humidity is about 10 per cent greater at the floor due to the lower temperature.

TABLE 1

Air velocity, cooling power, temperature and humidity of oxygen chamber

\begin{tabular}{|c|c|c|c|c|c|c|c|c|}
\hline \multirow[b]{2}{*}{ Measurement of } & \multicolumn{2}{|c|}{ Head-end wall } & \multicolumn{2}{|c|}{ Foot-end wall } & \multicolumn{2}{|c|}{ Right wall } & \multicolumn{2}{|c|}{ Left wall } \\
\hline & $\begin{array}{l}1 \text { foot } \\
\text { from } \\
\text { roof }\end{array}$ & $\begin{array}{l}1 \text { foot } \\
\text { from } \\
\text { floor }\end{array}$ & $\begin{array}{l}1 \text { foot } \\
\text { from } \\
\text { roof }\end{array}$ & $\begin{array}{l}1 \text { foot } \\
\text { from } \\
\text { floor }\end{array}$ & $\begin{array}{l}1 \text { foot } \\
\text { from } \\
\text { roof }\end{array}$ & $\begin{array}{l}1 \text { foot } \\
\text { from } \\
\text { floor }\end{array}$ & $\begin{array}{l}1 \text { foot } \\
\text { from } \\
\text { roof }\end{array}$ & $\begin{array}{l}1 \text { foot } \\
\text { from } \\
\text { floor }\end{array}$ \\
\hline Temperature of dry bulb. & 63.0 & 55.8 & 63.0 & 56.2 & 64.0 & 56.5 & 62.5 & 56.3 \\
\hline Temperature of wet bulb. & 54.3 & 49.8 & 54.0 & 50.0 & 54.0 & 51.0 & 54.5 & 50.0 \\
\hline Relative humidity........ & 56 & 65 & 55 & 64 & 51 & 68 & 59 & 65 \\
\hline Dry kata $T \ldots \ldots \ldots \ldots \ldots$ & 76 & 62 & 74 & 63 & 78 & 63 & 72 & 62 \\
\hline Wet kata $T^{\prime} \ldots \ldots$. & 36 & 33 & 38 & 34 & 39 & 34 & 39 & 34 \\
\hline Cooling pH. ........ & 6.0 & 7.3 & 6.1 & 7.2 & 5.8 & 7.2 & 6.3 & 7.3 \\
\hline$\frac{H}{\Phi-t} \ldots \ldots \ldots \ldots$ & 0.173 & 0.175 & 0.177 & 0.174 & 0.173 & 0.175 & 0.180 & 0.177 \\
\hline Velocity, feet per minute.. & 14.5 & 15.5 & 16.5 & 15.5 & 14.5 & 15.5 & 18.0 & 16.5 \\
\hline
\end{tabular}

Note: In each instance measurements were taken 4 inches from the wall at its center

The heat loss from the wet kata is 12.6 millecalories per square centimeter per second. The cooling effect according to Hill could be roughly analyzed as following: 6 millecalories by evaporation, 3.3 millecalories by radiation and 3.3 millecalories by convection.

In a room which we have tested the dry kata heat loss was 3 millecalories with the window closed. The air velocity was too low to be measured. With the window open the cooling power increased to 6 and with the window widely open much higher figures were obtained, with parallel increase in wind velocity.

The velocity of air movement in the chamber varied from 14.5 to 
18.0 feet per minute. The margin of error is such as to include these variations, so that it may be said that the air velocity is approximately 16 feet per minute. The type of air movement corresponds to the window-ventilated room where the cold air comes in at the bottom and rises to the ceiling as it is warmed, differing radically from a unidirectional system of ventilation. In figure 3 a diagrammatic sketch is given of the air movement when the coils at the head-end and at

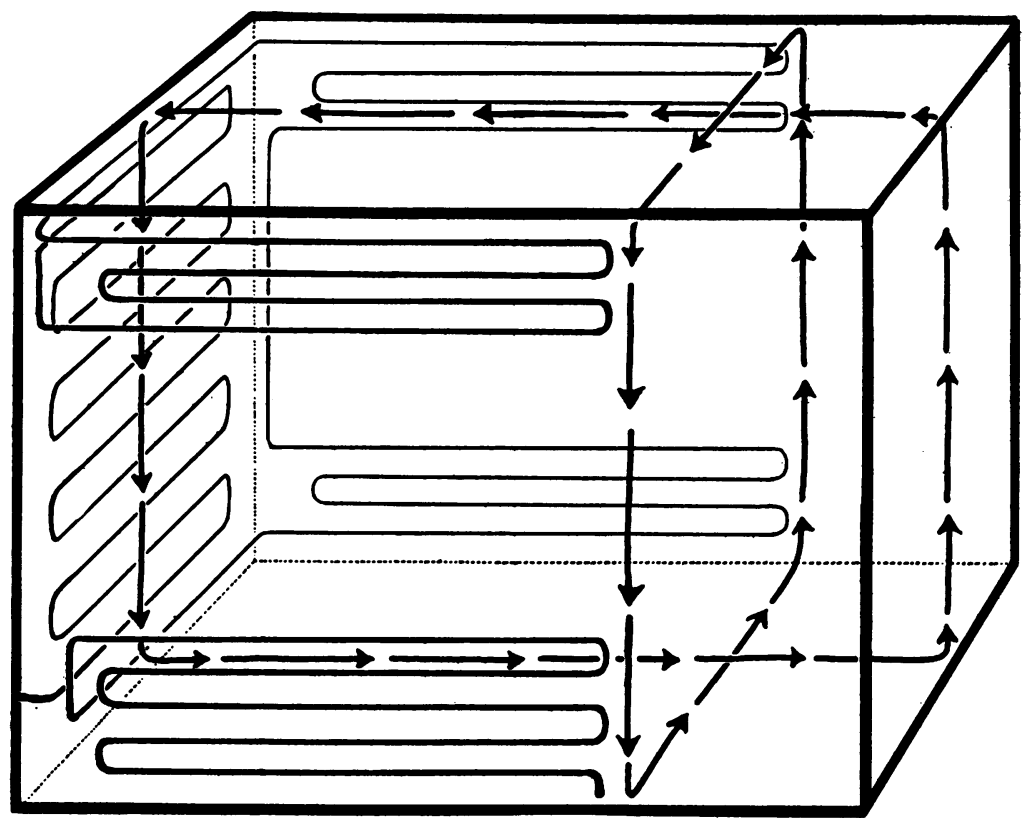

Fig. 3. Direction of Two Matn Convection Currents in Oxygen Chamber INDICATED BY ARROWS

one side are in use. The air at the head-end moves downward, traverses the floor underneath the bed, ascends the opposite end and returns along the roof to the head-end. Another current of air passes downward from the coils on one side to the floor, passes across to the opposite side, ascends to the roof and returns to its starting point. The heat of the patient's body is responsible for the warming of the air. Numerous eddies and cross-currents are naturally present, but 
the general movement of the air in the manner cited may be seen by blowing cigarette smoke against the various walls. (This experiment, it need hardly be cautioned, may be performed only when no oxygen has been added to the air.)

The carbon dioxide is removed as the air comes in contact with the soda-lime under the bed. The soda-lime box is made of copper screening of fine mesh, strengthened by strips of aluminum 1 inch in width. Two additional trays have been added to increase the speed and area of absorption although they are not really necessary. Fifty pounds of soda-lime last approximately one week. It is perfectly feasible to place enough soda-lime in the box to last three weeks of continuous use without stirring or renewing. The $\mathrm{CO}_{2}$ concentration is maintained below 0.5 per cent, although 1 per cent may be allowed as a maximum. Wilson soda-lime, 4 to 8 mesh, 15 per cent moisture should be employed. This is a very efficient carbon dioxide absorber and is sufficiently porous to allow the air to pass through it as well as over it. Fine mesh soda-lime, however, prevents free passage of air and is thus unsatisfactory for this purpose.

The condensation of water on the pipes has an additional advantage beyond that of maintaining the humidity within normal limits. Odors are apt to be condensed with the water, so that the chamber is absolutely free from all skin odors, as well as those which occur from excreta.

The temperature of the chamber may readily be kept 10 degrees lower than the atmosphere surrounding it. Thus, the room enclosing it in the hospital is maintained at $70^{\circ} \mathrm{F}$. and the chamber at $60^{\circ} \mathrm{F}$. During the summer the water from the faucet may be $8^{\circ}$ warmer than it is during winter, so that a temperature of $68^{\circ}$ to $70^{\circ} \mathrm{F}$. may obtain in the chamber. If more cooling is desired the water before entering the chamber will be made to pass through a copper coil packed in ice. No difficulty is anticipated aithough it has not as yet been used in the summer months. As a matter of fact, cooling in this type of chamber is as easily secured as those employing a unidirectional system of ventilation in which the air has to be taken out of the chamber and cooled.

The chamber is leak-tight when in use. In chambers in which the 
air has to be removed by pumps or fans leaks are apt to develop in the connections, the soda-lime containers or the refrigerating apparatus, or in the pumps themselves. With care these leaks can be removed or prevented, but our experience with the ventilation of tents has taught us that constant care is necessary. In this chamber in which all ventilation is secured inside the chamber leaks from this source do not occur.

The expense of the chamber is thus limited to the cost of the oxygen and soda-lime, which amounts to six to eight dollars a day. High pressure oxygen is employed (Linde Air Products). A reducing valve is used, specially calibrated to deliver oxygen in liters per minute (Oxweld Acetylene). Five 220 cubic foot tanks are connected to the valve by means of an oxygen manifold.

The chamber has been used in fifteen cases up to the present. Our intention is not to report the clinical results at this time but merely to state that it has proved satisfactory from the various points of view mentioned above. The management of the patient both from a nursing and medical point of view is unhampered. There is no machinery to get out of order. There is no source for sparks as no motors or pumps are employed. The running of the chamber is initiated and maintained by turning on the water and the oxygen.

\section{SUMMARY}

1. A new type of oxygen chamber is described in which there is adequate removal of carbon dioxide, moisture and heat without the use of motors, fans, electrical appliances or artificial refrigerating systems.

2. The inside of the chamber is lined in certain places by aluminum pipe which contains circulating cold water from the cold water faucet. The air in contact with the cold aluminum pipes is chilled, the moisture is condensed on the surface of the pipes, and the cool dry air passes to the floor of the chamber where the carbon dioxide is removed by contact with soda-lime. The air is warmed by the heat given off from the body of the patient and the process is repeated.

3. Data are presented which demonstrate that the chamber fulfils the modern requirements of scientific ventilation. Its effective temperature can be maintained below that ordinarily deemed necessary, 
namely, at $57^{\circ} \mathrm{F}$. The dry kata heat loss or cooling power is 6 millecalories per square centimeter per second. The velocity of air movement is 16 feet per minute.

4. The chamber is transportable. It is constructed of aluminum and glass panels in such a way as to be easily demounted and assembled without destroying its leak-tight property.

5. The operation of the chamber is simple and economical. By turning on the water and the oxygen the running of the chamber is initiated and maintained. The expense of up-keep is six to eight dollars a day. ${ }^{1}$

\section{BIBLIOGRAPHY}

1. Means, J. H.: Medicine, 1924, iii, 309. Dyspnea.

2. Lundsgaard, C.: Medicine, 1924, iv. Anoxemia in Lobar Pneumonia.

3. Barach, A. L.: Archives Int. Med., 1926, xxxvii, 186. Methods and Results of Oxygen Treatment in Pneumonia.

4. Stadie, W. C.: Jour. Exp. Med., 1922, xxxv, 337. The Treatmentof Anoxemia in Pneumonia in Oxygen Chamber.

Barcroft, J. H., Hunt, G. H., and Dufton, D.: Quart. Jour. Med., 1920, xiii, 179. The Treatment of Chronic Cases of Gas Poisoning by Continuous Oxygen Administration in Chambers.

Campbell, J. M. H., Hunt, G.H., and Poulton, E. P.: Jour. Path. and Bacteriol., 1923, xxvi, 234. An Examination of the Blood Gases and Respiration in Disease.

Binger, C. A. L.: Mod. Hosp., 1925, xxiv, 186. The Construction and Management of an Oxygen Chamber.

Boothby, Walter: Personal communication.

5. Sayers, R. R., and Harrington, D:: Reprint no. 854 from the Public Health Reports, July 20, 1923, 1616-1637. Physiological Effects of High Temperatures and Humidities with and without Air Movement.

McConnell, W. J., and Sayers, R. R.: Report of Investigations, Dept. Interior, Bureau of Mines, Serial No. 2584, March, 1924. Some Effects on Man of High Temperatures.

McConnell, W. J., and Yagloglou, C. P., assisted by W. B. Fulton: Reprint No. 977 from the Public Health Reports, December 5, 1924, 3075. Basal Metabolism Before and After Exposure to High Temperatures and Humidities.

${ }^{1}$ This oxygen chamber may be obtained from the Paramount Welded Alumjnum Products Co., 798 Wythe Avenue, Brooklyn, N. Y. 
6. Houghten, F. C., Yagloglou, C. P., and Sayers, R. R.: Report of Investigations, Dept. of Interior, Bureau of Mines. Serial No. 2563, January, 1924. Effective Temperatures for Still Air Conditions and their Application to Mining.

7. Hill, Leonard: The Science of Ventilation and Open Air Treatment. Published by Medical Research Committee, London, 1919.

Hill, L.: Proc. Physiol. Soc., 1919, 69. Metabolism and Cooling Power.

8. McConnell, W. J., and Yagloglou, C. P.: Reports of Investigations, Dept. of Interior, Bureau of Mines. Serial No. 2565, January, 1924. The Kata Thermometer-Its Value and Defects.

Seager, J. A.: Heat and Vent. Mag., 1915, xii, 24. Measure of Comfort in Factories. Construction and Use of Kata Thermometer.

Winslow, C. E. A.: Science, New Series, 1916, xliii, 1. The Kata Thermometer as a Measure of the Effect of Atmospheric Condition on Bodily Comfort. 